\title{
Introducción Histórica al Psychologismusstreit
}

[A Historical Introduction to Psychologismusstreit]

\section{Mario Ariel González Porta ${ }^{\Uparrow}$}

Resumen: Es una convicción usual, que el Psychologismusstreit fue una unidad indivisa que tiene como epicentro los "Prolegómenos" husserlianos y se concentra en la lógica. Esta convicción es falsa. El Psychologismusstreit fue un proceso en el cual se pueden y deben diferenciar etapas, tendencias y núcleos temáticos.

Palabras claves: psicologismo, polémica en torno al psicologismo, método psicológico, neokantianismo, platonismo

Abstract: It is commonly believed that the Psychologismusstreit was an indivisible unit that had as its epicenter the husserlian "Prolegomena" and focuses on logic. This is a false belief. The Psychologismusstreit was a process through which stages, tendencies and central themes can, and must, be differentiated.

Keywords: Psychologism, polemic surrounding psychologism, neokantianism, platonism

\section{1 - Introducción}

El Psychologismusstreit (PS) no es un proceso linear y unidimensional, sino que se caracteriza por poseer diferentes orígenes, motivaciones, vertientes y etapas 1 . Es esta característica peculiar del PS que deseamos estudiar en detalle en el presente trabajo. Mas, si de lo que se trata primariamente es de distinguir aspectos que son decisivos para constituir el horizonte del PS, esto no acontece, sin embargo, para mantenerlos separados, sino para interrelacionarlos y mostrar la complejidad de sus nexos. Lo que nos proponemos es algo así como una separación química de substancias para, de es-

\footnotetext{
${ }^{*}$ Professor titular da Pontifícia Universidade Católica de São Paulo (PUC-SP). E-mail: mariopor@pucsp.br. ORCID: https://orcid.org/0000-0001-8220-1540.

${ }^{1}$ Manifestación de lo anterior es que es un rasgo distintivo de esta polémica el no plantearse entre dos partidos previamente establecidos y claramente diferenciados, sino consistir en buena medida en el trazado de la línea divisoria entre ambos, de tal manera que lo que se entiende por psicologismo va variando a través del tiempo y autores considerados anti-psicologistas en un momento pasan a ser considerados psicologistas en otro, o autores que pueden ser considerados anti-psicologistas en una perspectiva, deben ser considerados psicologistas en otras. Por ejemplo, Stuart Mill es psicologista en lógica, pero no en semántica; Fries es psicologista en epistemología, pero no en lógica. Herbart, por otra parte, es antipsicologista con respecto a Beneke y Sigwart con respecto a Lipss pues consideran la lógica como ciencia normativa diferente de la psicologia. Ambos, sin embargo, son psicologistas desde el punto de vista de Frege, pues aceptan el principio de inmanencia (PI). Entenderé por PI la tesis cartesiano-lockeana de que el único objeto directo e inmediato de mi conocimiento son mis propias representaciones (Vorstellungen) o ideas (ideas).
} 
ta forma, entender mejor la interacción entre las mismas y obtener una comprensión más diferenciada del compuesto.

\section{2 - Consideraciones previas}

Aun cuando todo lo que habremos de decir colaborará a fijar el propio concepto de psicologismo, este es un presupuesto de nuestro trabajo y, por tanto, es exigible que ya en el comienzo establezcamos al menos una primera aproximación al mismo. Conviene distinguir entre concepto o definición $\mathrm{y}$ tesis. Entenderemos por "psicologismo" la reducción de leyes y/o entidades de cualquier tipo, a leyes $\mathrm{y} / \mathrm{o}$ entidades psicológicas (definición). Por tanto, el psicologismo es un tipo peculiar de reduccionismo. A partir de Husserl se sobreentiende que tal reduccionismo conduce al relativismo (tesis).

"Psicologismo" y "PS" son dos conceptos categorialmente diferentes: el primero se refiere a una teoría filosófica, el segundo, a un proceso histórico efectivo. Para que haya un PS es ciertamente una condición necesaria que haya psicologismo, pero la afirmación inversa es obviamente falsa, o sea, que puede haber psicologismo sin que haya PS. Si por psicologismo se entiende una teoría reduccionista del tipo que hemos definido, entonces no hay ninguna razón para limitar la aplicación de este concepto al s. XIX. Posturas, tendencias o deslices psicologistas se dejan constatar desde los primordios de la filosofía en Grecia. El PS, sin embargo, es un proceso que se concentra entre los comienzos de los siglos XIX y XX, que tiene su auge entre los años 1880 y 1920 y que posee como epicentro el ámbito lingüístico germánico, aun cuando no se limita a él, extendiéndose a Inglaterra, Francia e Italia. Este proceso es absolutamente sui generis y no tiene ningún paralelo en la historia de la filosofía anterior o posterior.

Existen dos perspectivas básicas posibles de abordaje del PS, a saber, la temático-sistemática y la histórica ${ }^{2}$, El trabajo que sigue se va a concentrar en la segunda, colocando principalmente el acento en cuestiones referentes al orden cronológico e interrelaciones factuales efectivas. Sin embargo, es justamente sobre la base de este estudio primariamente histórico, que cuestiones temáticosistemáticas recibirán una importante clarificación.

Del punto de vista histórico

\footnotetext{
${ }^{2}$ Debido a la distinción categorial que hemos subrayado conviene no confundir el estudio puramente sistemático del psicologismo con la perspectiva temático - sistemática en el estudio del PS.
} 
se debe establecer una distinción fundamental entre los orígenes y antecedentes del PS en el proceso que va del siglo XVII al XVIII, y el desarrollo de la polémica propiamente dicha en el siglo XIX y comienzos del XX. Con el primer punto nos ocupamos en el capítulo 3 , con el segundo en el 4.

\section{3 - Orígenes y antecedentes del PS}

En los orígenes del PS hay dos nombres se destacan, a saber, Descartes y Kant. Si todos los caminos conducen a Roma y, en el caso del PS, conducen a Husserl, todos ellos, así mismo, parten de Descartes y pasan por Kant, aun cuando, no obstante, no parten y no pasan de la misma forma.

El PS hunde sus raíces en la virada moderna a la subjetividad con Descartes y en la ulterior lectura empirista de esta virada, siendo posible distinguir en ella cinco elementos que de una forma $u$ otra juegan un rol decisivo: el establecimiento del PI, la apertura del way of ideas, la lógica de Port Royal, el inicio de la oposición entre concepción intuicionista y logicista de racionalidad y la central contraposición de experiencia interna y extern. Estos cinco elementos experimentan un desarrollo ulterior a través de Kant, en quien adquieren la forma específica de fenomenismo, distinción lógica-epistemológica quid facti - quid iuris, intuicionismo matemático y colocación de las bases del proceso de la constitución de la psicología como ciencia autónoma. Debido a este paralelismo, efectuamos en nuestra exposición un corte temático transversal $y$, partiendo en todos los casos de Descartes, llegamos en todos los casos a Kant.

\section{1. - PI - Inmanentismo - feno- menismo}

La virada moderna a la subjetividad está íntimamente vinculada al establecimiento del PI como punto de partida o presupuesto de toda filosofía. En realidad, él es una de sus derivaciones o implicaciones más fundamentales $y$, pese a todas las diferencias entre empirismo y racionalismo, común a ambos. Una consecuencia de la aceptación de este principio, o tal vez simplemente su contracara, es un cierto tinte idealista que se hace presente tanto en la variante racionalista, cuanto en la empirista.

Si el PI es un elemento característico del pensamiento moderno como tal, el convive desde Reid y la tradición escocesa con una tendencia minoritaria que mantiene vivo el realismo directo y se opone a todo representacionalismo. Esta tendencia está presente en el siglo 
XIX, vía Hamilton, en Stuart Mill.

Que el PI se establezca como principio dominante con la edad moderna y permanezca en tal función hasta fines del siglo XIX, no implica que estemos en presencia de una mera prolongación. En realidad, el PI adquiere en la filosofía alemana del siglo XIX algunos acentos específicos, que son decisivos para luego entender su papel en el marco del PS. Al menos cuatro inflexiones merecen ser subrayadas. Con Kant, el PI se radicaliza en el sentido de un fenomenismo que se extiende del mundo externo al interno, culminando en la tesis de que el sujeto sólo se conoce a sí mismo como fenómeno y no como cosa en sí. Con posterioridad a Kant, Reinhold, sitúa explícitamente el PI como fundamental en el horizonte de la filosofía alemana, al hacer del mismo la base última de la filosofía transcendental, correspondiendo a Schopenhauer, con su dualidad del mundo como representación y como voluntad, popularizarlo y a Müller, con su teoría de la energía especifica de los órganos sensoriales, dar pie a que se lo interprete fisiológicamente y se lo considera como científicamente fundado.

\section{2. - Del way of ideas al "método psicológico" (MP)}

\subsection{1. - De la isla al continente}

Con Locke se inicia no meramente al empirismo como una posición teórico-epistemológica, sino como una alternativa metódica al racionalismo. La oposición racionalismo - empirismo es vista en Alemania no primariamente como una oposición epistemológica, sino metódica, siendo el propio Kant pre-crítico un ejemplo paradigmático de este movimiento. La contraposición método matemático- método empírico, o método sintético - método analítico, se constituye en una línea divisoria fundamental en la filosofía alemana del siglo XVIII. Será justamente Kant, sin embargo, quien, llevando la discusión del plano primariamente metódico al propiamente epistemológico, establecerá claramente, a través de la distinción quid iuris - quid facti la cuestión "transcendental", esto es, dará un paso decisivo para liberar el problema de la objetividad de toda interpretación psicológico-genético (KANT: Ak., III, 99s.)

\subsection{2. - El MP en Alemania I: el surgimiento}

No obstante lo anterior, el esta- 
blecimiento de la idea de una reflexión transcendental, no pondrá un punto final a la cuestión en Alemania. Si no puede caber duda qué el MP tiene sus orígenes en la lectura empirista de la virada cartesiana a la subjetividad, tampoco puede ser dudado que él adquiere un perfil especifico en la filosofía alemana del siglo XIX.

Con Reinhold se inicia un movimiento revisionista del kantismo que transforma la filosofía crítica en un racionalismo apriorístico en el cual el criticismo deviene saber especulativo. Como reacción a este desenvolvimiento surge con Fries otra tendencia que intenta rescatar el elemento crítico frente al especulativo, el empirista frente al apriorismo radical, la autonomía de la ciencia y su carácter de Faktum frente a la pretensión de una filosofía como saber absoluto y, en definitiva, el dato y la correlativa reflexión frente a toda construcción.

La tendencia empirista de Fries tiene su fundamento en la consideración de la triunfante Naturwissenschaft $\mathrm{y}$, por tal razón, convive con una aceptación del elemento a priori (SM, p. 183). La tarea básica de la filosofía crítica es dar cuenta del mismo. Mas, auténticos principios no pueden en modo alguno ser probados, sino tan solo constatados. Esta constatación, por su vez, no puede ser sino empírica. En consecuencia, el método de la filosofía como crítica del a priori no puede ser ni transcendental ni especulativo, sino "psicológico" (RFS, p. 200ss.; NKV, I, p. 28ss.).

El MP friseano no consiste en una simple constatación de estados internos tendiente a establecer sus regularidades legales en el tiempo, sino que posee un abordaje estructural del psiquismo que ofrece cierta similitud con la intuición eidética husserliana. Él no procede, asimismo, por inducción (SM, p. 183; PS, p. 347), sino por "abstracción", efectuando un "análisis" del conocimiento dado que explicita y pone en evidencia sus presupuestos (NKV § 78, I, p. 38s.; § 97, p. 314s.; SM, §22, p. 99). Por reflexión a partir de una ley particular, por ejemplo, se "abstrae" el principio de causalidad.

En el argumento que conduce a la fundamentación de la filosofía en la psicología, juega un papel central la presuposición del PI. Sobre este base, Fries asume que, si todo conocimiento es una actividad del espíritu, el estudio del conocimiento es un estudio de la experiencia interna (SM, p. 104s). Mas, ¿qué se debe entender aquí por "conocimiento"? ¿No sería posible y necesario distinguir entre el conocer como proceso psicológico real (Erkennen) y el conocimiento como su contenido lógico- 
objetivo (Erkenntnis)? Hay pues en Fries una ambigüedad en el punto de partida que condiciona ulteriormente una ambigüedad en el proceso regresivo desarrollado a partir del mismo, de modo tal que la consideración puramente funcional de elementos lógicos del conocimiento se hipostasia en una teoría de las facultades (Vermögen). La crítica del MP y la evolución posterior del mismo se efectuará en la dirección de estas distinciones.

Si tomamos como referencia a Fries, podemos establecer el papel de Beneke en la evolución del MP apuntando sus diferencias con éste:

a. Para Fries, el MP es el método de la puesta al descubierto del a priori; para Beneke, propiamente de su disolución. Beneke es un empirista radical que, en última instancia, intenta derivar lo a priori de la experiencia. En la base de esta diferencia se encuentra otra, mucho más fundamental, referente la propia concepción del a priori: en tanto Beneke tiende a identificar a priori e innato, Fries lo combate de forma explícita en este punto, negando tal identificación y subrayando el carácter propiamente lógico de la precedencia (GPh, II, p. 514). b. Vinculado a lo anterior, mientras que Beneke tiene una concepción esencialmente genética de psicología, consistiendo su programa en última instancia en derivar todo de la sensación, Fries resiste explícitamente a tal tendencia (FRIES: NKV, I, p. 36-37; Beneke: LPsNW, p. 14ss.).

c. Del empirismo de Beneke y su perspectiva genética se sigue un reduccionismo radical. La psicología no es en Beneke simplemente la base de la filosofía en el sentido de su comienzo metódico, sino que ella es la filosofía (KPhAG, p. 89; SL, I, p. 35-42).

d. Si desde Fries era esencial al MP su carácter introspectivo, lo que era en este objeto de mención ocasional, se vuelve tema central en Beneke (VPsPh, p. 116-130; SM, p. 201; SL, II, p. 302). En esta radicalización influye decisivamente la situación externa. Beneke ya tiene frente a sí el rápido desenvolvimiento de la fisiología e, incluso, los primordios de su consecuencia fundamental, a saber, el Materialismusstreit. Dado que pretende ser espiritualista, Beneke resiste tenazmente a la disolución de la psicología en fisiología. Esta resistencia dará 
lugar a la idea de una "psicología pura", esto es, libre de elementos fisiológicos y basada exclusiva y consecuentemente en la percepción interna.

e. Beneke distingue claramente entre Naturwissenschaft y psicología en lo que dice respecto a su objeto y modo de acceso, concentrándose para ello en la oposición experiencia externa - experiencia interna; no obstante, inequívocamente orienta el proceder empírico de la psicología a la Naturwissenschaft. La psicología, como la Naturwissenschaft, aspira al establecimiento de leyes y se sirve para ello de un procedimiento "inductivo". Esta inducción parece por momentos poseer una cierta especificidad, aun cuando nunca queda totalmente claro en qué consiste positivamente ésta (LPsNW, p. 20).

\subsection{3. - El MP en Alemania II. La diversificación}

De Fries se derivará una escuela que, aun cuando con una significativa interrupción, se mantiene hasta las primeras décadas del siglo XX y que, en su primera fase, tiene como nombre de referencia a Apelt, en su segunda, a
Nelson. Esta escuela hará pocas y muy puntuales contribuciones a la doctrina original, motivadas por regla general por las diferencias de contexto científico y filosófico. Beneke, por su parte, aun cuando no forma una escuela en sentido estricto, encuentra eco en algunas figuras significativas de la generación siguiente (Überweg, Fortlage) y ejerce una importante, aun cuando difusa, influencia.

Una novedad realmente significativa aparece en las décadas del 60 y del 70 cuando, desde fuera de la tradición generada por Fries y Beneke, se comienza a delinear el fenómeno de una diversificación de tendencias dentro del MP, fenómeno que se prolonga en los años 80 . El primer motivo para esta diversificación será proporcionado por el positivismo, el cual incentiva el surgimiento de dos variantes "externalistas" del MP:

a. Si con Beneke comienza a existir una tensión entre el MP y la fisiología, esta tensión dará lugar a un desarrollo particularmente importante con Helmholtz, quien mantiene los principios de la interpretación psicológica de Kant, por un lado, pero, por otro, polemiza con el abordaje introspectivo, abriendo el MP a una integración de los resultados de la fisiología sin por ello 
incurrir en un reduccionismo fisiologista (ÜSM, p. 34-36, $85,118,189)$. La aceptación de procesos psíquicos inconscientes será elemento esencial para el mantenimiento de ese compromiso.

b. La segunda tendencia que debe ser aquí mencionada es la Völkerpsychologie de Lazarus e Steintahl, quienes siguiendo la misma inspiración externalista de Helmholtz, se proponen extender el herbartianismo al estudio de los fenómenos de la cultura (EGV, p. 1ss.).

El surgimiento de tendencias externalistas en el MP no va a significar el desaparecimiento total de sus variantes internalistas, sino, muy por el contrario, será acompañada por una renovación de las mismas. Para ello juega un papel decisivo la crítica del modelo científico natural. Si el MP comenzó con la intención de una psicología empírica, primero modelada en su idea de experiencia en la ciencia natural, su desarrollo termina conduciendo a una revisión del concepto de experiencia y a la negación de la identificación de método científico y método de la Naturwissenschaft. Esta revisión ya se anunciaba tímidamente en Fries, pero sin fructificar en la propuesta de una alternativa definida. Esta situación muda de modo radical con Dilthey (IBZP) y Brentano (DP), quienes defienden la idea de que un procedimiento auténticamente empírico debe ser adecuado a su objeto $y$, consecuentemente, exigen de la psicología un proceder descriptivo y estructural, claramente delimitado frente a perspectivas genéticas y explicativo-causales.

Como vimos, el MP surgió vinculado a una interpretación de Kant y se mantiene, de una forma u otra, ligado al kantianismo hasta la década del 70 cuando, la aparición del neokantianismo será decisiva para disputarle al mismo su interpretación de Kant, proponiendo una interpretación alternativa. A partir de ahora, ser kantiano y ser defensor del MP ya no son mas sinónimos.

Pero el neokantianismo no meramente contribuye a desligar el MP de la interpretación de Kant, sino de toda forma de idealismo, consolidando así, indirectamente, una tendencia que ya se venia anunciando desde Beneke, pero que va a culminar en la escuela de Brentano. Beneke es una figura decisiva no solo para entender el MP, sino para entender el PS y, esto, porque al mismo tiempo él es la forma más radical de psicologismo, por un lado, y, por otro, abre el camino para conciliar MP 
y realismo. Como todos los defensores del MP, Beneke presupone la validad irrestricta del PI, efectúa sin embargo una importante precisión pues si bien mantiene el fenomenismo kantiano con respecto al mundo externo, afirma que en el auto-conocimiento el sujeto accede a una realidad en sí. Su argumento básico, que anticipa el del archienemigo del psicologismo Frege, reza: no todo puede ser Vorstellung (SM, p. 69; NGM, p. 9). Lo anterior implica replantear la perspectiva eminentemente epistemológica, esencial al MP en su origen friseana, abriendo la posibilidad de una variante ontológica del mismo. El MP ya no es meramente un camino para una refundamentación de la teoría del conocimiento, sino también de la metafísica como saber del en-sí.

\subsection{4. - PS y MP}

Debemos distinguir entre Psicologismo y MP, entendiendo por el primero, como ya hemos hecho, una tesis filosófica, por el segundo, por el contrario, una postura puramente metódica, en principio neutra con respecto a cualquier tesis o teoría filosófica específica. La distinción entre psicologismo y MP permite colocar explícitamente una cuestión discutida intensamente en el siglo XIX, referente a si el MP conducía necesariamente o no al psicologismo. Un aspecto bien definido pero poco estudiado del Psychologismusstreit giró, no en torno a una discusión entre psicologistas y anti-psicologistas, sino entre anti-psicologistas y defensores del MP.

En tanto que los autoproclamados anti-psicologistas, tendieron a suponer sin más la identidad de psicologismo y MP, algunas variantes del MP resistieron tal identificación y se consideraron a sí mismas antipsicologistas, como es el caso de la tendencia realista-metafísica plasmada en la escuela de Brentano. Mas si las variantes realistas del MP tendieron al antipsicologismo, las variantes idealistas tendieron al psicologismo. Esta diferencia se va a profundizar con el surgimiento de la logische Frage.

\section{3. - La evolución de la lógica de Port Royal a la logische Frage}

Sabidamente, la filosofía moderna se inicia con la crítica del método escolástico y el proceder silogístico y la correlativa exigencia de una reorientación metodológica de la ciencia. Por tal razón, aun cuando de su pluma nunca surgió un texto que tratase de lógica, ni una contribución significativa en este campo, Descartes es 
una figura decisiva en la historia de esta disciplina por interrumpir el desenvolvimiento continuo que se venía efectuando a partir de la lógica aristotélica y establecer las bases de un nuevo rumbo.

Un producto fundamental de este movimiento para el desarrollo posterior fue la lógica de Port Royal3, la cual presenta tres elementos que merecen especial destaque en el actual contexto, a saber, la idea de que la lógica es esencialmente una técnica que se propone orientar procesos mentales y que, por tanto, tiene estos como objeto, idea esta que se concretiza en dos formas características: por un lado, en una cierta concepción semántica de lo que sea la significación de términos y, por otro, en la identificación de leyes lógicas y leyes del pensamiento.

La tradición iniciada por la lógica de Port Royal termina por ser predominante en el siglo XVIII, desplazando la aristotélica. Ella, sin embargo, va a tener su decisiva interrupción en Kant, quien, siguiendo el camino iniciado por Leibniz, critica expresamente la tendencia moderna en la lógica, considerando en una famosa pasaje que sus contribuciones y enriquecimientos simplemente des- conocen el verdadero objeto de la disciplina, de forma tal que más la desfiguran que la enriquecen $y$, sobre esa base, vuelve a la idea de una lógica general (Ak., III, p. 8).

De la virada kantiana se nutre directamente el resurgimiento de la lógica formal promovido por Herbart en el comienzo del siglo XIX, el cual, sin embargo, prontamente tiene que enfrente ar un nuevo enemigo: la lógica metafísica hegeliana.

Logische Frage en sentido estricto denomina la polémica desatada por Trendelenburg contra Herbart y Hegel, esto es, tanto contra la determinación de la lógica como disciplina formal, como contra su interpretación metafísica en base a la tesis de la identidad de ser y pensar. Ahora bien, la discusión de Trendelenburg con Herbart y Hegel es el horizonte de referencia de todo lo que se escribe en la lógica alemana de los años posteriores y, en particular, en las décadas del 80 y 90. Las lógicas de este período parten de un similar status questionis, procurando distanciarse simultáneamente del formalismo herbartiano y del metafisicisimo hegeliano (Sigwart, Erdmann, Wundt y Lipps). Es como reacción a la identificación hegeliana de ló-

\footnotetext{
${ }^{3}$ Vamos a contar una historia abreviada y en buena medida esquemática, siendo que muchas de nuestras afirmaciones no soportarían un análisis histórico más rigoroso. Si la lógica de Port Royal inicia una tradición, no siempre esta tradición se nutre directamente de ella. Un papel fundamental juega en Alemania la lógica hamburguesa de Jungius, que es el modelo directo de muchos manuales de lógica del siglo XVIII (BOSCHENSKI, 1976, p. 270)
} 
gica y metafísica que se desata en Alemania una marcada tendencia inmanentista que, potenciando el rol central del PI mucho más allá del seguimiento o no del programa específico del MP, lleva a una restricción de la lógica al ámbito del pensar (Denken) y que, si en un primero momento, con Lotze, se limita a negar el carácter objetivoreal de categorías lógicas fundamentales afirmado por Hegel (como concepto o silogismo), termina motivando la insistencia en el carácter de las leyes lógicas como "leyes del pensamiento" (Denkgesetze). Es este acento en la limitación de la lógica al Denken, lo que provocará, no solo una cierta tendencia laxa al idealismo, que revierte en buena medida el movimiento iniciado por Beneke, sino al relativismo.

\section{Psicologismusstreit $\mathrm{y}$ logische} Frage no pueden ser identificados, mas están en estrechísima relación pues justamente las derivaciones de la logische Frage jugaron un papel esencial para incentivar una nueva oleada de psicologismo. El psicologismo de los lógicos en los 80' y 90', con su relativismo antropológico característico, no es primariamente el resultado de la tradición de Port Royal o del desarrollo del MP, sino del cruzamien- to de este último desenvolvimiento, primariamente en sus variantes idealistas, con aquel desencadenado por la logische Frage.

\section{4. - Intuición}

Con Leibniz se inicia en el racionalismo un proceso de diversificación en dos corrientes con dos concepciones eminentemente diferentes de racionalidad que podríamos llamar de "intuicionista" y "logicista" ${ }^{4}$, o de una concepción en la cual racionalidad está íntimamente vinculada a la idea de evidencia y otra en que la racionalidad está vinculada a principios objetivos (identidad y nocontradicción). Estas dos concepciones de racionalidad se proyectan en dos modos de concebir la inferencia como remitiendo, en un caso, a una sucesión de intuiciones discontinuas, en el otro, a la idea de algoritmo.

La oposición entre una concepción intuicionista o logicista de racionalidad está estrechamente vinculada a una diferente concepción de la relación entre racionalidad y subjetividad. En la concepción intuicionista, el sujeto epistemológico, a través de la idea de evidencia, es indisociable de la racionalidad, en tanto en la otra, se-

\footnotetext{
${ }^{4}$ Nos servimos de una oposición terminológica ya consagrada en el ámbito de la filosofía de las matemáticas y le damos un sentido más general.
} 
parable, tendiéndose de una forma $\mathrm{u}$ otra a variantes de platonismo.

Con Kant, esta oposición entre dos concepciones de racionalidad pasa a replantearse sobre la forma de una oposición entre pensamiento y sensibilidad. Si Kant claramente toma partido por la concepción leibniziana de racionalidad, identificada con la analiticidad, la idea de intuición no pierde su importancia, sino que se traslada del plano intelectual al sensible.

Las diferentes concepciones de intuición y de la relación de intuición y racionalidad en Descartes, Leibniz y Kant, están íntimamente vinculadas a diferentes concepciones de matemática. Estas diferencias desenvuelven todo su potencial en el s. XIX con la artimetización del cálculo y, posteriormente, con el surgimiento de las geometrías no-euclideanas y sus derivaciones. Si, en Newton, la fundamentación última del cálculo remitía a la intuición temporal y Kant, dada su admiración incondicional por Newton, aceptaba tal idea sin cuestionamiento, en el siglo XIX se procesa un movimiento de logización de las matemáticas que, volviendo a Leibniz, termina eliminando cualquier idea de intuición de su fundamentación.

La tendencia logicista, que, en última instancia, sobre diferentes formas, se inclina a la postulación de objetos abstractos, va a ser un fuerte factor para el surgimiento de un platonismo con contornos peculiares en el siglo XIX. El platonismo del siglo XIX en la lógica está indisociablemente vinculado al logicismo en las matemáticas, desde Bolzano, a Frege y Husserl. Junto con la eliminación de la intuición, el logicismo elimina la necesidad de una consideración esencial de la subjetividad en la fundamentación de las matemáticas y tiende a asumir una dirección objetivista que lo termina colocando en estrecha relación con el platonismo.

\section{5. - Psicología después de Kant: de la psicología como ciencia fundamental de la filosofía a la psicología como ciencia autóno- ma}

Si el siglo XIX es el siglo de la constitución de la psicología como ciencia, esta constitución se dará en el transfondo de presupuestos establecidos en los siglos XVIIXVIII, a saber:

a. La virada cartesiana a la subjetividad en la filosofía moderna, la lectura empirista de esta virada por Locke y la idea de una ciencia de la naturaleza humana correlata de la $\mathrm{Na}$ turwissenschaft por Hume. 
b. La constitución de la ciencia natural como ciencia empírica independiente de la filosofía.

c. La clasificación de las ciencias de Wolff con su distinción entre psicología racional como parte de la metafísica especial y psicología empírica 5 .

d. La negación de la posibilidad de la metafísica como ciencia por parte de Kant y, por tanto, de la psicología racional.

e. y su negación de que la psicología empírica pueda constituirse como una ciencia equivalente a la ciencia natural (Leary, 1978 y 1982).

Como en la filosofía de las matemáticas, el status questionis establecido por Kant en la "Crítica de la razón pura" es el punto de partida de la polémica en torno a la psicología o Psychologiestreit, esto es, de la discusión que lleva a la constitución de la psicología como ciencia autónoma en el siglo XIX.

Aun cuando PS y Psychologiestreit son procesos que se encuentran interligados y presentan numerosas interacciones, ellos no pueden ser sin más identificados.
Ciertamente, la constitución de la psicología como ciencia autónoma es un factor importante para explicar tanto la prioridad cuanto la intensidad que asume el PS en el s. XIX. Sin embargo, el no es el único factor pues, como ya hemos insinuado, la logische Frage y el desenvolvimiento de las matemáticas no son menos decisivos.

No menos importante que distinguir PS y Psychologiestreit, es el distinguir entre dos sentidos de la expresión MP. La expresión "MP" tiende a ser usada desde fines del siglo XIX y comienzos del XX en el sentido de "método de la psicología", o sea, para referirse a la cuestión de cual deba ser el modo de proceder de una cierta disciplina para constituirse como ciencia autónoma. En mediados del siglo XIX, sin embargo, dicha expresión tiene un otro sentido usual referente a cuál deba ser el método de la filosofía, cuestión ésta generalmente colocada en el horizonte de una caracterización de la filosofía como ciencia que asegure su derecho a existencia en la llamada "crisis de identidad" 6 , La idea básica es qué si toda ciencia debe fundarse en la experiencia y la

\footnotetext{
${ }^{5}$ Investigación psicológica ciertamente existió antes de Descartes, pero no es arbitrario establecer un interés especifico en la subjetividad a partir de él. Investigación psicológica, por su vez, existió obviamente antes de Wolff, pero es el sistema de clasificación de las ciencias de Wolff, lo que va a dar a la psicología su lugar característico como disciplina, a partir del cual debe ser entendido el proceso de su constitución como ciencia autónoma.

${ }^{6}$ Claro que los proponentes del MP tenían también propuestas con respecto a cuál debía ser el método de la psicología, pero la inversa no vale: muchos actores decisivos en el debate en torno al método de la psicología no tuvieron interés en la cuestión del MP.
} 
Naturwissenschaft trata de la experiencia externa, corresponde a la filosofía fundarse en la experiencia interna. En este sentido, la expresión "MP" fue originariamente el opuesto, primero, del método especulativo propio del idealismo alemán, después, del método transcendental neokantiano $y$, finalmente, del método fenomenológico. Mas, si, como vimos, la idea del MP constituye en la filosofía alemana como alternativa de perfil especifico a partir de la obra de Fries y Beneke, la expresión "MP", sin embargo, fue solo introducida décadas después por Bona Meyer (KPs, p. 122) y popularizada por sus oponentes neokantianos.

\section{4 - El desarrollo del PS}

Si damos una mirada retrospectiva al conjunto de lo expuesto y lo unificamos, tenemos que decir que si Descartes puede ser considerado el inicio remoto del psicologismo, Kant puede ser considerado el inicio próximo del movimiento anti-psicologista $y$, esto, tanto en el plano de la epistemología, cuanto en el plano de la lógica, pues en ambos, establece la distinción fundamental quid fac- ti - quid iuris y procura mantener separadas cuestiones de génesis y de validez (Geltung) (Ak, III, p. 8, 99s.). Ahora bien, en tanto que el anti-psicologismo kantiano en la lógica va a ser decisiva para el platonismo del siglo XIX, el anti-psicologismo kantiano en la epistemología va a ser decisivo para el neokantianismo7.

Con lo dicho llamamos la atención sobre un aspecto medular del PS que tiende a ser pasado por alto, a saber, que se pueden $y$ deben diferenciar claramente dos vertientes en el mismo que provienen de una diversa raíz histórica que, en última instancia, remite a Kant en dos formas característicamente diferentes, tienen un relativo grado de autonomía en su desarrollo histórico efectivo y se distinguen claramente por el acento temático-sistemático que asume el anti-psicologismo en cada una de ellas.

Mas, si bien no cabe duda de que Kant está en el origen de las dos formas principales del antipsicologismo del siglo XIX, solo pasamos del anti-psicologismo kantiano al anti-psicologismo característico del siglo XIX a través de mediaciones que, por su vez, son diferentes según se tra-

\footnotetext{
${ }^{7}$ Si en estos dos planos Kant contribuye decisivamente al anti-psicologismo, existe un tercero, a saber, aquel referente a la intuición, en el cual Kant está en el inicio de una variante psicologista que tiene su base en la discusión sobre la teoría del espacio (Helmholtz).
} 
ta, del tipo de anti-psicologismo kantiano y del tipo de antipsicologismo del s. XIX que con este se relaciona. En tanto que del anti-psicologismo kantiano en la lógica se deriva el platonismo presente en el PS, esto no acontece sino a través de la logische Frage, de la logizicación del cálculo y, en última instancia, de la confluencia conflictiva de ambos procesos. Por su vez, en tanto que del antipsicologismo kantiano en la epistemología se deriva el neokantianismo, esto no acontece sino a través del MP $\mathrm{y}$, en buena medida, del surgimiento de ciertas variantes específicas del mismo como la psicología fisiológíca y Völkerpsychologie. Veamos ahora estos procesos en mayor detalle.

\section{1. - La vertiente platónica del antipsicologismo}

Uno de los primeros capítulos del PS o, tal vez, el primer capítulo, es el producto de la retomada de la idea kantiana de una lógica general, libre de elementos psicológicos, a través de Herbart, por un lado, y por Bolzano, de otro 8 . Pero, este anti-psicologismo no puede ser entendido sin mas como una mera continuación del kantiano, pues hay en él elementos nuevos que lo van a distinguir claramente del kantiano, a saber, su vies platónico. Mas, aun cuando tanto Herbart como Bolzano son en cierto sentido "platónicos", el tipo de platonismo es diferente, no menos que, en definitiva, su propia concepción de lógica.

Si Herbart distingue claramente lógica y psicología, lo hace como una distinción de dos puntos de vista sobre la misma realidad, en última instancia psicológica, no como una distinción entre dos esferas de objetos, reales y abstractos (PsW, § 120, p. 160161) 9 . Justamente por lo anterior, si Herbart afirma aparentemente la identidad del elemento ideal en la multiplicidad de sus realizaciones subjetivas, ese elemento ideal es concebido como limes de aproximación de procesos psíquicos reales, no como objetos en-si existentes.

Bolzano, entre tanto, es el primero que introduce claramente la idea de que la lógica es el estudio de objetos abstractos ${ }^{10}$. Su diferencia esencial con Kant, pero también con Herbart, es que el portador de verdad deja de ser

\footnotetext{
${ }^{8}$ Con Herbart se da un paso decisivo a la constitución del PS como polémica (Streit) a través de su discusión con Beneke y, posteriormente de éste con Drobisch.

${ }^{9}$ Vinculada a esto está su idea de la normatividad esencial de la lógica.

${ }^{10}$ Con esto, ya en el propio inicio del PS el concepto de psicologismo muda, fenómeno éste que aún habrá de repetirse varias veces. Véase nota 1.
} 
el juicio y pasa a ser la proposición, motivo por el cual ésta y no aquel se constituyen en el objeto de la lógica (WL, $\S 24,25$ ). Mas aún, con esta mudanza el platonismo va a introducir una dimensión propiamente semántica en el anti-psicologismo que no estaba presente en ninguna forma ni en Kant ni en Herbart, más que será esencial para el desarrollo posterior el mismo. A partir de ahora, el anti-psicologismo lógico y el semántico se desenvuelven en estrecha unión. El platonismo de Bolzano, a diferencia del de Herbart, está esencialmente vinculado al programa logicista derivado de la nueva situación de las matemáticas y la aritmetización del cálculo.

Este platonismo exigido por la consolidación de una tendencia logicista derivada de la evolución de las propias matemáticas, sin embargo, entra en rota de colisión con el inmanentismo antimetafísico derivado de la logische Frage y sus apelos francamente relativistas. Si el primer elemento era decisivo en el platonismo de Bolzano, el segundo lo será en el de Frege y, posteriormente, en el de Husserl. Será primariamente este relativismo psicologista derivado de la logische Frage lo que dará al PS su forma canónica definitiva $\mathrm{o}$, al menos, mas conocida. El psicologismo en la lógica que
Frege y Husserl critican no tiene su única, y ni siquiera su más importante fuente en la tradición de Port Royal o del MP, sino en las derivaciones de la logische Frage.

Mirado retrospectivamente, en el proceso del PS con respecto a la lógica se dejan diferenciar claramente tres momentos, a saber, la reacción kantiana a la lógica moderna y su prolongación en Herbart, el platonismo bolzaniano reflejo del logicismo matemático, y el platonismo fregueanohusserliano, reflejo de una reacción ulterior al relativismo antropológico derivado de la logische Frage.

\section{2. - La vertiente neokantiana del antipsicologismo}

Si en Kant el problema epistemológico se anuncia en su especificidad, es con el neokantianismo que esta idea es desenvuelta en todas sus consecuencias de modo tal que el criticismo deviene "método transcendental" (COHEN, KTE1, p. 124-127; KTE2, p. 296299, 373-379, 601-602; WINDELBAND: KGM, p. 318ss.; WPh, p. 58-59; RIEHL: ÜBFph, p. 31, 65; $\mathrm{PhK}, \mathrm{I}, \mathrm{V}, \mathrm{p} .8)$. Este hecho marca decisivamente la peculiaridad del anti-psicologismo característico del neokantianismo. La gran diferencia entre la vertiente platónica y la neokantiana del anti- 
-psicologismo es que si la primera se concentra en la lógica y por derivación esencial en la semántica (aun cuando, segundo los casos, no desconoce totalmente la epistemología), la segunda se concentra en la epistemología y desconsidera o ignora la dimensión propiamente lógica y/o la semántica.

Existe una extendida concepción de que el PS es un fenómeno que gira primariamente en torno a la lógica. Esto es falso y deja fuera de consideración un capítulo fundamental del mismo protagonizado por el neokantianismo. Todas las diferencias decisivas entre la vertiente neokantiana y la platónica del anti-psicologismo desaparecen si decimos sumariamente que el psicologismo consistió en una psicologización de la lógica y pasamos por alto el hecho decisivo de que:

a. en un caso, la lógica es lógica general o formal, en el otro, transcendental y

b. que la lógica transcendental neokantiana es sinónimo de epistemología.

Para entender lo que realmente significa lo anterior, tenemos que tener en cuenta cuatro puntos:

a. Para el neokantianismo el concepto de "lógica" se define en el horizonte de la oposición primariamente epistemo- lógica entre el pensar y la intuición sensible.

b. La intuición sensible, incluso en sus formas puras espacio y tiempo, no es para el neokantianismo una fuente autosuficiente de conocimiento, no pudiendo ser considerada de forma desligada del pensar. Por tal razón, para un neokantiano, la epistemología no consiste en dos capítulos autosuficientes, una estética y una lógica transcendental.

c. Pero, si la intuición no puede ser desligada del pensar, este pensar, por su vez, no puede ser desligado de su función de estar al servicio de la objetivación de los fenómenos, esto es, del conocimiento $\mathrm{y}$, por tanto, la propia idea de una consideración del pensar en sí o de una lógica formal separada de la lógica transcendental, no hace sentido.

d. Dicho de otra forma, en el neokantianismo la lógica general y la estética transcendental, pierden su autonomía y pasan a estar subordinadas y/o esencialmente vinculadas a la lógica transcendental, la cual, por tal razón, termina siendo identificada con epistemología.

Ahora, el hecho de que el antipsicologismo kantiano no sea un 
anti-psicologismo lógico- formal, sino esencialmente epistemológico, está vinculado a tres elementos de extrema importancia para efectuar un estudio diferenciado el PS, a saber:

a. El psicologismo que el neokantianismo combate en primera instancia no es aquel derivado de la logische Frage, como sucedía con el platonismo del siglo XIX, sino aquel vinculado al MP y sus derivaciones.

b. El antipsicologismo neokantiano, y por dirigirse a la epistemología y no a la lógica general, es un anti-psicologismo que tiene esencialmente por objeto las formas puras de intuición, espacio y tiempo, pues fueron estas las que jugaron un rol decisivo para psicologizar a Kant a partir de Müller y a través de los descubrimientos fisiológicos hasta Helmholtz 11 .

c. Si el anti-psicologismo neokantiano se opone característicamente al psicologismo de las formas pura de la intuición, no se limita a ellas, sino que se extiende al Denken. Lo hará, sin embargo, únicamente en cuanto el Denken es un instrumento de objetivación de los fenómenos. Justamente por ello, lo que está en el centro de la atención no es el principio de identidad y no contradicción sino de causalidad.

\section{3. - Relaciones entre anti- psicologismo platónico y neo- kantiano}

Tan importante como es el distinguir claramente las dos vertientes principales del anti-psicologismo, y los tipos de psicologismo que ellas respectivamente combaten, lo es el estudiar la relación entre las mismas. Las diferentes concepciones de lógica de neokantianismo y realismo lógico están en última instancia vinculadas a diferentes concepciones de la teoría del a priori y de las matemáticas.

a. Para el neokantianismo existe conocimiento a priori, siendo uno de los objetivos principales del movimiento el fundamentar el mismo frente a los ataques empiristas y positivistas. El conocimiento a priori de los neokantianos, no obstante, no es, como en el platonismo, conocimiento de objetos abstractos o supraempíricos, sino conocimiento

\footnotetext{
${ }^{11}$ Frege, por el contrario, nunca estuvo preocupado con el problema del psicologismo en el espacio.
} 
de las condiciones de la posibilidad de la experiencia y, por tanto, jamás se desliga de ella para adquirir la forma de una logische Erkenntnisquelle autónoma como en Frege.

b. La diferente concepción del a priori entre el platonismo y el neokantianismo se expresa en forma paradigmática en sus diversas concepciones del saber matemático. Dicho de forma más general, pero también más precisa: el neokantianismo tiene un punto de coincidencia y un punto de diferencia esencial con el realismo lógico. La coincidencia radica en que, en tanto ambos son receptivos de la evolución de las matemáticas, ambos son "logicistas', esto es, niegan cualquier papel de las intuiciones puras de espacio y tiempo en la fundamentación de las matemáticas y pretenden fundar las mismas en el pensar (Den$k e n)^{12}$. Solo que en un caso se trata de un formales Den$k e n$, en el otro de un transzendentales Denken. Esto motiva una diferencia esencial en la concepción de las matemáticas que se expresa en el jargón neokantiano en la oposición entre "teoría" y "méto- do". En tanto para los realistas lógicos la matemática es una teoría que trata de una esfera especifica de objetos, los abstractos, para los neokantiano, la matemática es método, o sea, un conjunto de procedimientos y/o instrumentos de objetivación de los fenómenos $y$, en consecuencia, en última instancia, siempre referidos y nunca separable de los objetos empíricos (Cohen: PIM). La consecuencia de lo anterior es que para los neokantianos el problema de la aplicación de las matemáticas a la física, eventualmente sobre la forma de un pasaje de enunciados analíticos a sintéticos, es simplemente un problema mal planteado.

Si hasta ahora hemos trabajado con una oposición entre neokantianismo y platonismo, conviene observar que esta oposición no es totalmente exacta y seria mas justo decir que la diferencia aquí presente es una diferencia entre dos tipos de platonismo vinculados a dos tomas de posiciones esencialmente diversas en la cuestión del chorismo y que tienen su expresión paradigmática en las dos grandes interpretaciones de Platón del siglo XIX propuestas por

\footnotetext{
${ }^{12}$ Es importante no perder de vista que los neokantianos nunca fueron sin más kantianos, sino que mantuvieron importantes diferencias con Kant vinculadas siempre a su atención al Faktum de la ciencia.
} 
Natorp y por Lotze. En tanto que Lotze desontologiza Platón, Natorp va más allá y lo transzendentaliza para legitimar su peculiar lectura platonizada de Kant.

En su comentario a los "Prolegómenos" husserlianos, Natorp no dejaba de manifestar una cierta extrañeza frente al impacto de estos $y$, no sin toda razón, afirmaba que el neokantianismo nada tenia a aprender der Husserl (Natorp: FLM, p. 271). Esta observación natorpiana obliga a la pregunta del porqué del fulminante impacto del primer volumen de las "Investigaciones lógicas". No vamos a agotar esta cuestión aquí, pero es importante establecer algunas observaciones al respecto. Desde el punto de vista estrictamente histórico-cronológico, las primeras etapas del PS se concentran en la lógica y están vinculadas al anti-psicologismo platónico. Posteriormente, la vertiente platónica recibe un nuevo impulso con Frege, para alcanzar toda su madurez con Husserl. Entre ambos momentos, sin embargo, acontece un fenómeno peculiar que es la verdadera explosión que se opera en el PS a partir de la década del 70. Este fenómeno está esencialmente vinculada al neokantianismo y seria incomprensible sin éste. En efecto, un factor decisivo para que el PS ocupe durante tanto tiempo el primer lugar en la agenda de la discusión filosófica, fue el hecho que la crítica del psicologismo era esencial para el triunfo del método transcendental frente al psicológico, por un lado, por otro, que este triunfo dice, ya no respecto a un problema filosófico particular (por ejemplo, a la cuestión referente a una filosofía de las matemáticas), sino respecto del propio destino de la filosofía y su especificidad como disciplina. Mas, a la fase programática, sigue en el neokantianismo una fase institucional que termina resultando en el casi absoluto dominio de la universidad alemana. Cuando se estudia el problema del PS, no hay que olvidar nunca que, si del punto de vista de sus consecuencias y proyecciones en el siglo XX, Frege y Husserl son figuras decisivas y mucho más importantes que el Neokantianismo desde el punto de vista del siglo XIX, el neokantianismo tiene una total preeminencia, de forma tal, que solo a través de él, el PS pudo tomar la dimensión que efectivamente tomó. El impacto de las "Investigaciones lógicas" husserlianas se construye sobre una historia que ya comenzó a ser escrita por el neokantianismo y su novedad no consistió en plantear el tema, sino en focalizarlo directamente, a la luz de los resultados de la logische Frage, en el relativismo 
y no ya en el $\mathrm{MP}^{13}$.

\section{5 - Más allá de las variantes neo- kantiana y platónica}

Con la distinción entre dos variantes fundamentales en el antipsicologismo presente en el PS, no hemos agotado en forma alguna las distinciones decisivas que deben ser hechas, sino dado simplemente un primer esquema ordenador. Sobre su base, es posible introducir otras distinciones, que suponen la anterior más al mismo tiempo la refinan y completan.

\section{1. - Antipsicologismo semánti- co y problema del sentido. Las diferentes formas del problema de la objetividad en el s. XIX}

Ya hemos observado que no hubo en el neokantianismo un interés particular en el combate al psicologismo semántico. Esto no es producto de un cierto descuido, sino una derivación sistemáticamente necesaria a partir del modo en que se construye el problema de la objetividad en dicho movimiento. A partir de Frege es usual distinguir entre el sentido y el valor de verdad de un enunciado $y$, junto con esta distinción, el distinguir, ulteriormente, entre el problema de la fundamentación de la objetividad del valor de verdad y el problema de la fundamentación de la objetividad del sentido. El pensamiento alemán pre-fregueano, sin embargo, está dominado por el concepto de validez (Geltung), el cual se refiere primariamente a la cuestión de la objetividad epistemológica (resumido a su más simple expresión en el neokantianismo en el concepto de "ley") y solo de modo indirecto, secundario e inespecífico a la cuestión de la objetividad del sentido.

Esta situación comienza a experimentar una mudanza significativa a partir de los años 90'. En efecto, el desarrollo de las Geisteswissenschaften (GW) pone en evidencia que la cuestión del sentido lingüístico es meramente un aspecto de la cuestión mucho mas general del sentido en la enorme diversidad de las manifestaciones culturales. De tal forma, el problema colocado primeramente en la lógica a través de la distinción entre el juicio, el enunciado y la proposición experimente una decisiva ampliación. Con esta surge un nuevo capítulo del PS, que tiene a Dilthey y a la escuela de Baden co-

\footnotetext{
${ }^{13}$ Obsérvese la diferencia de perspectiva de Natorp Objektive und subjektive Methode y los Prolegómenos de Husserl. Lo que está en el centro de la atención de Natorp es mostrar la primacía del método transcendental y, en consecuencia, del proceder objetivo sobre el subjetivo. En Husserl lo que está en el centro de atención son, por un lado, los presupuestos, por otro, las consecuencias del psicologismo como posición filosófica.
} 
mo principales protagonistas. Lo anterior no significa decir, sin embargo, que con esta polémica ya se establezca en el neokantianismo la crítica del psicologismo semántico como central, sino, únicamente, que se abre un camino que, en figuras como Rickert, termina culminando en una creciente atención a la cuestión de la objetividad del sentido. En los años noventa, la resistencia neokantiana al psicologismo del MP en las GW diltheano asume aún caracteres más "clásicos", tomando como horizonte una ampliación del concepto de validez (Geltung) que lleva a introducir como central la noción de valor (Wert).

Pero, si, por un lado, conviene percibir la especificidad de un problema del psicologismo concentrado en las GW, por otro, conviene también no perder de vista los vínculos esenciales que este psicologismo posee con aquel que se plantea en la lógica. El reconocimiento de la especificidad de las Geisteswissenschaften es un proceso que está íntimamente vinculado a la discusión en torno a los fundamentos de la lógica: tanto en un caso como en otro, el problema de la objetividad del sentido tiende a delinearse con contornos propios frente al problema más clásico de la verdad.

\section{2. - Objetivismo y subjetividad}

Pese todas las diferencias que existen entre las dos vertientes del anti-psicologismo mencionadas hasta ahora, hay algunos rasgos comunes que motivan una similar (aun cuando no absolutamente idéntica) objeción de parte de los psicologistas y que se deja resumir en el título "objetivismo", con el cual se apunta a subrayar desconsideración del carácter en última instancia subjetivo del conocimiento. La línea de confrontación entre psicologistas y antipsicologistas tiene una de sus expresiones más importantes en la oposición "objetivismo"- relativismo.

Si comenzamos con el antipsicologismo de cuño platónico, digamos que ya Exner objetaba a Bolzano, que la admisión de "representaciones en sí", objetivas e irreales, nos enfrenta al problema irresoluble de cómo un sujeto real, como en última instancia lo es el sujeto del conocimiento, puede acceder a algo que, de principio, no es real, una objeción que, obviamente, tiene su raíz última en la presuposición incondicional del PI, o sea, en este caso, en que solo puedo captar lo que de algún modo es real "en mí" (Exner a Bolzano 10/12/1834, p. 74-75 y 78). Bolzano intenta varias respuestas a esta objeción, pero ninguna es convincente, en última instancia, 
porque en todas ellas no consigue evidenciar el supuesto de Exner, concediendo a este sin más los derechos de una psicología naturalista. La crítica de Exner a Bolzano se repite en términos prácticamente idénticos entre Kerry (ÜAPsV. IV, p. 305) y Frege, con la gran diferencia que ella terminará llevando a Frege a una decisiva profundización de su posición (FREGE: L (1897), p. 157; GGA, I, p. XIVss.).

La tendencia objetivista de los anti-psicologistas se mantiene, aun cuando en otra variante, en la vertiente neokantiana, siendo decisiva tanto en Cohen cuanto en Windelband (BRELAGE, 1965, p. 94-95). Como consecuencia de su tajante distinción de todo lo psicológico, la así llamada "conciencia transcendental" deviene en realidad una mera façon de parler, que no expresa otra cosa que el conjunto sistemático de principios de validez. No obstante, surgirá de las propias filas neokantianas, y por un proceso inmanente, el intento de superación de esta tendencia. Natorp es el primero en comprender que, al fin de cuentas, una filosofía transcendental sin sujeto es un sin-sentido y que toda crítica al psicologismo que no dé cuenta de su justa exigencia subjetiva, estará condenada al fracaso. Por tal razón, Natorp concentra su crítica al psicologismo en una crítica del concepto psicologista de subjetividad (ÜOSM, p. 285-286; EPs, § 13-15). Su tesis fundamental, que lo opondrá al psicologismo no menos que al "logicismo" radical de Cohen, reza: el psicologismo es la consecuencia de una falsa teoría de la subjetividad, propia del naturalismo ( $y$, en última instancia del dualismo) $y$, por tanto, solo puede ser definitivamente superado si se supera esta. Sobre esta base, la salida que Natorp propone es disolver la rígida oposición sujeto-objeto, presupuesta en toda visión naturalista de la subjetividad, substituyéndola por una oposición relativa entre subjetivación y objetivación como diferentes direcciones en que se puede considerar un único proceso fundamental. Si el sujeto no puede ser simplemente eliminado, el sólo puede ser integrado coherentemente en el horizonte de la reflexión filosófica si no se contradicen los principios del método transcendental, o sea, el carácter de la filosofía como discurso de segunda orden. Por tanto, la subjetividad tiene que ser tematizada en un procedimiento reconstructivo a partir de la objetividad y en estricta correlación con la misma (NATORP: AP, p. 213).

Si queremos entender el desenvolvimiento posterior que tomará la lucha antipsicologista y, en particular, el papel que Frege y Hus- 
serl habrán de desempeñar en la misma, tenemos que observar que, junto con el mencionado cambio fundamental, existe en Natorp un otro punto en el cual él conserva el status quo, a saber, en el mantenimiento del PI. En tal sentido, salvemos del olvido un hecho importante, a saber, que en 1894, cuando Twardowsky escribe su histórico texto "Sobre contenido y objeto de la representación", Natorp le dedica una reseña en donde del contexto surge que él considera que Twardowsky se encuentra en la dirección errada (NATORP, BDSE, II, p. 198-201), impresión ésta que se reafirma si se atiende a la correspondencia con Husserl de esa época (Hua, Briefwechsel. Band V, p. 39-58) y se confirma definitivamente en textos posteriores (AP, p. 153).

Pues bien, un año antes, en 1893, en el prefacio de las GGA en su crítica de Erdmann, Frege es el primero que en el horizonte de la filosofía alemana del siglo XIX, abandona el PI ${ }^{14}$. Esta decisiva virada, claro está, quedará totalmente opacada a la luz de la centralidad que la cuestión de una perspectiva subjetiva adquiere en la fenomenología husserliana. La crítica husserliana del psicologismo en los "Prolegómenos", no debe ser vista como un todo autosubsistente, sino que se prolonga y completa en el segundo volumen de "Investigaciones lógicas" con la propuesta de una elaborada teoría de la subjetividad coherente con las exigencias del platonismo ${ }^{15}$.

El movimiento iniciado por $\mathrm{Na}$ torp en el neokantianismo marburgués tiene un cierto paralelo, aun cuando más tardío, en el neokantianismo de Baden con Rickert (ZWE) y una interesante radicalización en Högnigswald (PDPs) quien levanta la tesis de la no incompatibilidad de principio y hecho (Prinzip und Tatsache), tanto en el caso del yo como del lenguaje.

\section{3. - Fenomenología transcen- dental - facticidad}

Como debería ser sabido, pero es generalmente ignorado, la crítica husserliana al psicologismo ni termina ni culmina en 1900, sino que acompaña todo el desarrollo de Husserl y experimenta una novedad decisiva con la des-

\footnotetext{
${ }^{14}$ El papel de Frege en el PS es sistemáticamente mal comprendido: su radical antipsicologismo no excluye, sino que supone una cierta idea de subjetividad. El centro de su crítica a Husserl en PhA es justamente que este, como la casi totalidad de los discípulos de Brentano en esta época, mantiene expresamente la afirmación del PI (HUSSERL: Hua, XII, p. 94).

${ }^{15}$ Obviamente que, en este desarrollo, Natorp ha jugado un papel fundamental y, tal vez, Frege ha hecho una contribución decisiva.
} 
cubierta de la reducción y la virada al idealismo fenomenológicotranscendental (Husserl: Hua, XXIV, p. 209ss.). Con esto aparece una nueva variante de antipsicologismo que tiene un perfil especifico distinto de todas aquellas ya existentes e, incluso, obliga a repensar con más exactitud las distinciones de las cuales partía$\operatorname{mos} 16$.

En la variante fenomenológicotranscendental del anti-psicologismo, si bien se da cuenta por extenso de la relación subjetividad - objetividad, los problemas del anti-psicologismo anterior no desaparecen sino que se trasladan de la relación de un sujeto concebido psicológicamente a un objeto concebido platónicamente, a la relación entre subjetividad psicológica y transcendental, un problema que ya, como vimos, se anunciaba en Natorp, pero que ahora se radicaliza por la propia reducción.

La búsqueda de una mediación entre ambas subjetividades permea la última etapa del pensamiento de Husserl con su concepción monádica del sujeto transcendental que introduce nociones tales como Verweltlichung,
Verzeitlichung y Verräumlichung (HUSSERL: Hua, III/1, p. 67; VII, p. 71), pero solo alcanzará todo su desarrollo cuando, a través de la polémica en torno al artículo de la Enciclopedia Británica, Heidegger introduzca la tesis de que el verdadero sujeto transcendental es el sujeto fáctico en su facticidad y comience a desenvolver ésta en el horizonte de un replanteo general de las relaciones entre el ser y el tiempo ${ }^{17}$.

\section{4. - Objetivismo, psicologismo refinado $y$, nuevamente, $M P$}

Si con Natorp, el anti-psicologismo marburgués se desenvuelve en la dirección de una consideración subjetiva, existen formas de antipsicologismo, como las representadas por Bauch, que se desenvuelven en la dirección exactamente contraria. Su idea básica es que la lucha contra el psicologismo debe ser radicalizada, pues en todas las formas de pretendido anti-psicologismo, inclusive pues en la escuela de Marburgo, permanece un "psicologismo refinado" (verfeinerter Psychologismus), el cual debe ser superado, si la lu-

\footnotetext{
${ }^{16} \mathrm{Si}$ sobre el criterio de Frege, quien aceptaba el PI era psicologista, sobre el criterio de Husserl, quien no efectúa la reducción es psicologista y, por tanto, también Frege. Ver nota 1.

${ }^{17}$ Con esto adquiere su última expresión el proceso iniciado por Beneke y desenvuelto por Lotze y la escuela de Brentano en el siglo XIX.

${ }^{18}$ En base a lo dicho podríamos diferenciar en la lucha anti-psicologista del neokantianismo institucional por lo menos tres etapas, una primera, la de los fundadores del programa, una segunda de los discípulos destacados
} 
cha debe llegar a su fin (IKPhAG, p. 141. Compare LASK: LU, p. 171 y MOOG, LPsPs, p. 53, 77)

Dentro del horizonte descripto, otro capítulo importante es protagonizado en la escuela de Brentano en la cual el objetivismo adquiere una variante realista $y$ no-transcendental, sobre la forma de la Gegenstandstheorie de Meinong, la cual se propone programáticamente una "consideración a-psicológica" (apsychologische Betrachtung) del objeto y de la verdad.

Así como Bauch se ve conducido en el neokantianismo a una polémica con Natorp, Höfler, siguiendo a Meinong, se ve conducido en la escuela de Brentano a una polémica con Marty, quien reconociendo la necesidad y legitimidad de la lucha anti-psicologista, resiste sin embargo a toda substitución del MP por la Gegenstandstheorie y su propuesta de eliminar toda consideración subjetiva (HÖFLER: ÜA, p. 216, 219; MARTY: UG, p. 304, 307). A esta tendencia dirige la acusación de "Apsychologismus", para diferenciarla del Anti-psychologismus, que, como ya indicamos, también la escuela de Brentano pretende defender.

Si efectuamos ahora una visión retrospectiva tenemos que observar que si cuando se trata el PS la atención tiende a concentrarse en el conflicto entre psicologistas y anti-psicologistas, este conflicto, es un aspecto particular, ciertamente central y esencial, de un todo más abrangente. Así como existió una reacción antipsicologista al psicologismo reinante, existió, además de la reacción psicologista, una reacción al antipsicologismo, considerado ahora como mero antipsicologismo u objetivismo.

\section{6 - Conclusión}

En las líneas que anteceden hemos puesto en evidencia que el PS lejos de haber sido, como generalmente se tiende a creer, una unidad indivisa concentrada en la lógica y con epicentro en los "Prolegómenos" husserlianos, fue un proceso en el cual se pueden y deben diferenciar etapas, tendencias, núcleos temáticos y líneas de evolución.

Rickert y Natorp, que integran la perspectiva subjetiva en el horizonte transcendental y aún una tercera, que con Hönigswald y Bauch van en direcciones no solo diferentes, sino opuestas. 


\section{Referências}

BAUCH, Bruno. Immanuel Kant und die Philosophische Aufgabe der Gegenwart. Beitrage Philosophie des Deutschen Idealismus, III, 1925, p. 7-18 (IHPhAG)

BENEKE, F. Eduard. 1822. Neue Grundlegung zur Metaphysik als Programm zu seinen Vorlesungen über Logik und Metaphysik dem Druck übergeben. Berlin: Posen, in Commission bei E. G. Mittler. (NGM) .1832. Kant und die philosophische Aufgabe der Gegenwart. Eine Überdenkschrift auf die Kritik der reinen Vernunft. Berlin: Posen Bromberg. (KPhAG)

1840. System der Metaphysik und Religionsphilosophie. Aus den natürlichen Grundverhältnissen des menschlichen Geistes abgeleitet. Berlin: Ferdinand Dümmler. (SM)

BERGMAN, Julius. 1892-1893. Geschichte der Philosophie Bd. 1-2.

. 1842. System der Logik als Kunstlehre des Denkens. Berlin. (SL)

. 1852. "Das gegenwärtige Verhältnis zwischen der Psychologie und der Physiologie." Archiv für pragmatische Psychologie II: 116-38. (VPSPH)

2006. (1877). Lehrbuch der Psychologie als Naturwissenschaft. Berlin: Elibron Classics /Berlin: Ernst Siegfried Mittler und Sohn. (LPsNW)

BOLZANO, Bernhard. Wissenschaftslehre. Sulzbach, Wolfgang Schulz, 1837. (WL)

BOSCHENSKI, I. M. 1976. Historia de la lógica formal. Madrid: Gredos.

BRELAGE, Manfred. Transzendentalphilosophie und konkrete Subjektivität. In: BRELAGE, Manfred: Studien zur Transzendentalphilosophie. Berlin, 1965.

BRENTANO, Franz. 1971. Psychologie vom empirischen Standpunkt. 2 Bde. Hamburg: Felix Meiner. (PES)

. 1982. Deskriptive Psychologie. hrsg. V R. M. Chisholm u. W. Baumgartner. Hamburg: Meiner. (DP)

COHEN, Hermann. 1871. Kants Theorie der Erfahrung. Berlin: Dümmler. 2da. Aufl. 1885. (KTE1, KTE2)

. Das Prinzip der Infinitesimal-Methode und seine Geschichte. Ein Kapítel zur Grundlegung der Erkenntniskritik. Berlin, 1883. (PIM) DILTHEY, Wilhelm. 1984. Das Wesen der Philosophie. Hamburg: Meiner. (WPh) 
. 1990. "Einleitung in die Geisteswissenschaften. Versuch einer Grundlegung für das Studium der Gesellschaft und der Geschichte". In Gesammelte Schriften (1913-1958). Bd. 1. 9. Auflage. Hrsg. Groethuysen. Göttingen: Vandoeck and Ruprecht. (EGW) . 1990. "Ideen über eine beschreibende und zergliedernde Psychologie (1894)". In Gesammelte Schriften (1913-1958). Bd. V, 4 Aufl. Hrsg. Georg Misch. Göttingen: Vandoeck and Ruprecht. (IBZPs)

FISCHER, Kuno. 1862. Die beiden kantischen Schulen in Jena. Stuttgart: Cottascher Verlag. (bKS)

FREGE, Gottlob. Die Grundlagen der Arithmetik. Eine logisch mathematische Untersuchung über den Begriff der Zahl. Hamburg, Meiner, 1988 (GA).

. Grundgesetze der Arithmetik. Jena, Pohl, 1893 (GGA).

. Logik (1897). In: Frege, G.: Nachgelassene Schriften. Edited by Gottfried Gabriel, Walter Rödding, Hans Hermes, Friedrich Kambartel, and Friedrich Kaulbach. Hamburg: Felix Meiner Verlag, 1969. p. 137-163. (L(1897))

FRIES, J. Friedrich. 1803. Reinhold, Fichte, Schelling. Leipzig: August Lebrecht Reineicke. (RFS)

. 1811. "System der Logik. Ein Handbuch für Lehrer und zum Selbstgebrauch." Book Renaissance. Heidelberg: Mohr und Winter. (SL).

1819. Grundriss der Logik. Ein Lehrbuch zum Gebrauch von Schulen und Universitäten. Heidelberg: Mohr und Winter, 2te. verbesserte Auflage. (GL) (NKV)

. 1824. Polemische Schriften. 2 Bde. Hallen und Leipzig: Reinecke and Comp. (PS)

. 1824. System der Metaphysik. Heidelberg: Christiana Friedrich Winter. (SM)

. 1834. Geschichte der Philosophie. Halle: Verlag der Buchhandlung des Weisenhauses. (GPh)

. 1935. Neue oder anthropologische Kritik der Vernunft. 3. Bde. Berlin: Verlag Öffentliches Leben. (NKV)

HELMHOLTZ, Hermann. 1903. "Über das Sehen des Menschen." Ein populär wissenschaftlicher Vortrag gehalten zu Könisberg in Preussen. Zum Besten von Kants Denkmal. Am 27. Februar 1855. Leipzig, Voss, 1855. In Vorträgen und Reden. 4te. Aufl. Brauchschwieg, F. Vieweg und Sohn. (ÜSM). 
HERBART, J. Friedrich. 1993. Lehrbuch zur Einleitung in die Philosophie. Hamburg: Meiner Verlag. (LEPh)

. 2003. Lehrbuch zur Psychologie. Königsberg, August Wilhelm Unzer. 1816. Ed. Margret Kaiser - el Safti. Würzburg: Königshausen and Neumann. (LPs)

. Psychologie als Wissenschaft. Neu begründet auf Erfahrung, Metaphysik und Mathematik. Hersg. Hartenstein. Leipzig, Leopold Voss, 1850. (PsW)

HUSSERL, Edmund. Briefwechsel Brentano Schuler. Husserliana Dokumente, III/1Briefe.

. Philosophie der Arithmetik. Mit ergänzenden Texten (1890-

1901). Ed. Lothar Eley. The Hague. Martinus Nijhoff, 1970. Husserliana, XII. (Hua, XII).

. Briefwechsel. Band V. Die Neukantianer. Hua - Dokumente. Dordrecht / Boston / London, Kluwer, 1994.

. Logische Untersuchungen. Zweiter Band. Erster Teil. Untersuchungen zur Phänomenologie und Theorie der Erkenntnis. Ed. Ursula Panzer, The Hague, Martinus Nijhoff, 1984. Husserliana, XIX/1. (Hua, XIX/1)

. Ideen zu einer reinen Phänomenologie und phänomenologischem Philosophie. Erstes Buch: Allgemeine Erfahrung in die reine Phänomenologie. Rev. Ed. Karl Schuhmann. The Hague: Martinus Nijhoff. 1976 Husserliana, III/1. (Hua, III/1)

. Erster Philosophie (1923-1924). Zweiter Teil. Theorie der phänomenologischen Reduktion. Ed. Rudolf Boehm. The Hague: Martinus Nijhoff, 1959, Husserliana, VIII. (Hua, VIII)

. Einleitung in die Logik und Erkenntnistheorie. Vorlesungen 1906-1907. Ed. Ulrich Melle. Dordrecht Martinus Nijhoff, 1987. Husserliana, XXIV. (Hua, XXIV)

HÖNIGSWALD, Richard. Die Grundlagen der Denkpsychologie. Studien und Analysen. München, 1921. 2. Auflag. Leipzig-Berlin, 1925. (GDPs)

KANT, Immanuel. Kritik der reinen Vernunft. Kants gesammelte Schriften. Hsg. Von der Preussischen Akademie der Wissenschaften. Berling 1902ss. Vol. III, IV (AK)

KERRY, B. Über Anschauung und ihre psychische Verarbeitung. Vierter Artikel, Vierteljahresschrift für wissenschaftliche Philosophie, 11, 1887, pp. 249-307 (ÜApsV).

LASK, Emil. Die Lehre vom Urteil. Tübingen, 1912. (LU) 
LAZARUS, Moritz. 1860. "Einleitende Gedanken über Völkerpsychologie". Zeitschrift für Völkerpsychologie und Sprachwissenschaften I: 1-73. (EGV)

LEARY, David E. The psychological development of the conception of psychology in Germany 1780-1850. Journal of History of Behavioral science, 14, 1978, 113-121;

. The psychology of Jakob Friedrich Fries (1773-1843): its context, nature and historical significance. Storia e critica della psicologia, vol. III, No. 2, 1982, 217-248

LIEBMANN, Otto. 1912. "Kant und die Epigonen. Eine kritische Abhandlung". In Herausgegebene von der Kantgesellschaft. Ed. Bruno Bauch. Berlin: Reuther and Reichard. (KE)

LIPPS, Theodor. 1883. Grundtatsachen des Seelenlebens. Bonn: Verlag von Max Cohen und Sohn. (GT)

LOTZE, Herman. Logik Drei Bücher vom Denken vom Untersuchen und vom Erkennen. Misch, Georg (ed.). Leipzig, Meiner, 1912 (L).

. Die Philosophie in den letzten 40 Jahren (1880). In: LOTZE, Hermann: Logik Drei Bücher vom Denken vom Untersuchen und vom Erkennen. Misch, Georg (ed.). Leipzig, Meiner, 1912, pp. XCIVCXXII.

MARTY, Anton. 1908. Untersuchungen zur Grundlegung der allgemeinen Grammatik und Sprachphilosophie. Halle: Niemeyer. (UG)

MEYER, Jürgen Bona. 1870. Kants Psychologie. Dargestellt und erörtert. Berlin: Verlag von Wilhelm Hertz. (KPs)

MOOG, Willy. Logik, Psychologie, Psychologismus. Wissenschaftssystematischen Untersuchungen. Halle, Nyemeier, 1919. (LPsPs)

NATORP, Paul. 1912. Allgemeine Psychologie nach kritischer Methode. Erstes Buch: Objekt und Methode der Psychologie. Tübingen: Verlag von J. C. B. Mohr. (AP)

1888. Einleitung in die Psychologie nach kritischer Methode. Freiburg: Verlag von J. C. B. Mohr. (EPs)

Über objektive und subjektive Methode. Philosophische Monatshefte, XXIII, 1887, pp. 257-286 (ÜOSM).

. Bericht über deutsche Schriften zur Erkenntnistheorie aus den Jahren 1894 und 1985. Archiv für systematische Philosophie. Erstes Stück: 3, 1897, pp. 101-121; Zweites Stück: 3, 1897, pp. 193-209; Drittes Stück: 3, 1897, pp. 391-402 (BDSE).

Zur Frage der logischen Methode. M. Bez. auf E. Husserls, Prolegomena zur reinen Logik". Kant Studien, 6, 1901, pp. 270- 
283 (FLM).

. Platos Ideenlehre. 2da. Aufl. Leipzig, 1921 (PI)

REINHOLD, K. Leonhard. Versuch einer neuen Theorie des menschlichen Vorstellungsvermögens. 2te. Auflage. Prag und Jena, C. Widtmann und I. M. Mauke, 1796 (Versuch).

. Beiträge zur Berichtigung bisheriger Missveständnisse der Philosophen. Erster Band. Hamburg, Felix Meiner, 2003 (Beiträge).

Rickert, Heinrich. Der Gegenstand der Erkenntnis. Ein Beitrag zum Problem der philosophischen Transzendenz. Freiburg, Mohr, 1892 (GE). . Zwei Wege der Erkenntnistheorie. Transzendentalpsychologie und Transzendentallogik. Halle, Kaemmerer, 1909. (ZWE)

RIEHL, Aloys. 1872. Über Begriff und Form der Philosophie. Eine allgemeine Einleitung in das Studium der Philosophie. Berlin: Carl Dunckers Verlag. (ÜBFPh)

1876. Der philosophische Kritizismus und seine Bedeutung für die positive Wissenschaft. 2. Bde. Leipzig: Verlag von Wilhelm Engelmann. (PhK)

STUMPF, Carl. 1892. Psychologie und Erkenntnistheorie. München: Verlag der K. Akademie. (PsE)

. 1924. "Selbstdarstellung." R. Schmidt, Hrsg. Die Philosophie der Gegenwart in Selbstdarstellungen. 5. Band: 204-65. Leipzig; Meiner. (SD)

2011. Erkenntnislehre. Lengerich: Pabst Science Publishers. (EL) TWARDOWSKI, K. 1982/1894. Zur Lehre von Inhalt und Gegenstand der Vorstellung. Eine psychologische Untersuchung. München: Philosophia Verlag / A. Hölder. (ZL)

WINDELBAND, W. 1884. "Kritische oder genetische Methode?" In Präludien. Aufsätze und Rede zur Philosophie und ihrer Geschichte. Tübingen: Verlag von J.C.B. Mohr, 3a. 318-54, 1907. (KGM) . 1884. "Was ist Philosophie". In Präludien. Aufsätze und Rede zur Philosophie und ihrer Geschichte. Tübingen: Verlag von J.C.B. Mohr 3a. 24-77, 1907. (WPh)

Recebido: $29 / 06 / 2019$

Aprovado: 08/08/2019

Publicado: $17 / 11 / 2019$ 
